\title{
ZONAL ALLOCATION FOR THORACIC ORGANS IN THE UNITED KINGDOM: HAS IT BEEN SUCCESSFUL? A SINGLE-CENTER VIEW
}

Tarek Aziz, FRCS

Malcolm Burgess, MRCP

Ali Rahman, FRCS

Colin Campbell, FRCS

Abdul Deiraniya, FRCS

Nizar Yonan, FRCS
Objectives: The purpose of this study was to analyze the impact of the zonal allocation system for thoracic organs on the outcome of our transplant activity. Methods: We analyzed the results of thoracic transplants performed between 1987 and 1998. The transplants were divided into 3 groups: local donors retrieved by our team (171 hearts and 61 lungs; DL group); distant donors retrieved by our team (58 hearts and 35 lungs; DD group); and distant donors retrieved by other teams (51 hearts and 41 lungs; DX group). Results: No significant differences were observed among the groups in early postoperative events for either heart or lung transplantation. Heart transplants: Cardiac index was $2.6 \pm 0.4 \mathrm{~L} / \mathrm{m}^{2}$ for the DL group, $2.7 \pm 0.6 \mathrm{~L} / \mathrm{m}^{2}$ for the DD group, and $2.5 \pm 0.7 \mathrm{~L} / \mathrm{m}^{2}$ for the DX group $(P=.4)$. The 30-day mortalities were $9.1 \%, 9.1 \%$, and $8.3 \%(P=.5)$ and the 1 -year survivals $83 \%, 80 \%$, and $82 \%(P=.4)$ for the DL, DD, and DX groups, respectively. Lung transplants: Alveolararterial oxygen gradient was $358 \pm 19 \mathrm{~mm} \mathrm{Hg}$ for the DL group, $345 \pm$ $17 \mathrm{~mm} \mathrm{Hg}$ for the DD group, and $329 \pm 21 \mathrm{~mm} \mathrm{Hg}$ for the DX group $(P$ $=.07)$. The 30-day mortalities were 9.9\%, 10.5\%, and $12.8 \%(P=.2)$ and the 1-year survivals $79 \%, 75 \%$, and $77 \%(P=.3)$ for the $D L, D D$, and DX groups, respectively. Conclusion: Zonal allocation for thoracic organs has been successfully applied to our program. Using donor organs retrieved by other teams, we have achieved equivalent outcomes for both heart and lung transplantation. (J Thorac Cardiovasc Surg 1999;118: 733-9) $\mathrm{n}$ recent years thoracic organ transplantation has become an effective therapy for patients with endstage cardiorespiratory disease. As an increasing number of centers have participated in thoracic organ transplantation, more thoracic surgeons have learned the techniques of procurement and implantation for heart, lung, and heart-lung transplantation. Before November 1993 in the United Kingdom, each of the 8 thoracic transplant centers sent their own teams to the donor hospital for retrieval. Zonal organ allocation for thoracic organ procurement has since been introduced. ${ }^{1}$ Each center has a geographic zone containing a popula-

From the Cardiac Transplant Unit, Wythenshawe Hospital, Manchester, United Kingdom.

Received for publication Jan 12, 1999; revisions requested April 9, 1999; revisions received May 5, 1999; accepted for publication June 14, 1999.

Address for reprints: N. Yonan, FRCS, Cardiac Transplant Unit, Wythenshawe Hospital, Southmoor Rd, Manchester M23 9LT, United Kingdom.

Copyright $(\odot) 1999$ by Mosby, Inc.

0022-5223/99 \$8.00+ $0 \quad \mathbf{1 2 / 1 / 1 0 0 7 4 4}$ tion of between 4 and 13 million people (Fig 1) depending on the local transplant activity. It has both first refusal of organs in the zone and an obligation to retrieve organs that cannot be used locally. The primary aim of this system is to avoid coupled retrieval to allocation, minimize delay in donor procedures, and diminish unnecessary movement of retrieval teams.

During the past 5 years we have used donor hearts and lungs retrieved by other teams when the distant cardiothoracic surgeon was comfortable in performing retrieval for us. This study aimed to investigate whether the use of donor thoracic organs retrieved by other teams under the regulation of the zonal allocation scheme affected the outcome of thoracic organ transplantation in our center.

\section{Patients and methods}

We analyzed the results of 451 consecutive thoracic organ transplantation procedures (280 orthotopic hearts, 73 single lungs, 32 double lungs, and 34 heart-lung blocks) performed at Wythenshawe Hospital, Manchester, United Kingdom, between April 1987 and November 1998. Organs were divid- 


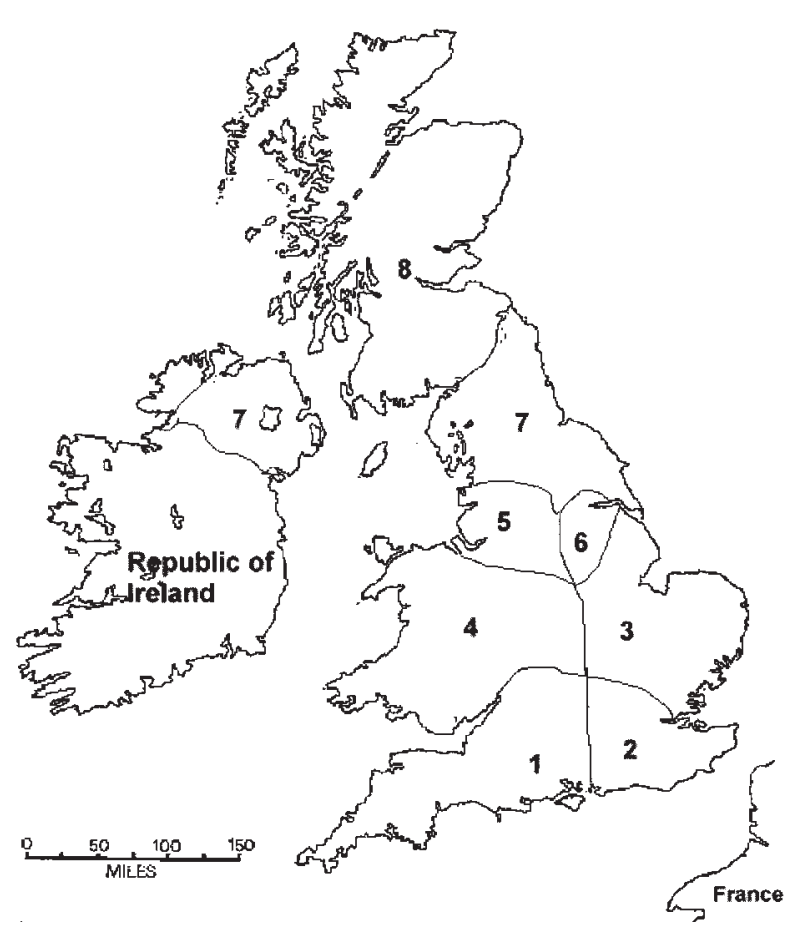

Fig 1. The zonal division of the United Kingdom to 8 locations. Wythenshawe hospital is area 5.

ed into 3 groups: (1) organs from local donors retrieved by our team (171 hearts, 61 lungs, and 19 heart-lung blocksDL group); (2) organs from distant donors retrieved by our team (58 hearts, 35 lungs, and 14 heart-lung blocks-DD group); and (3) organs from distant donors retrieved by another team (51 hearts, 41 lungs, and 1 heart-lung blockDX group).

Heart re-transplantation and heterotopic heart transplant recipients were excluded from the study. Follow-up was complete to December 1998 or to the time of recipient death. Mean follow-up was $77 \pm 35$ months for heart transplant recipients and $39 \pm 12$ months for lung recipients.

Donor selection. As in other United Kingdom transplant centers, donor selection criteria at our center have been liberalized to attract a larger donor pool. It has already been demonstrated that marginal heart and lung donors can be optimized with careful intensive care management and successfully used for selected recipients. ${ }^{2}$ The criteria for selection of heart and lung donors are widely established ${ }^{3,4}$ and approved by the United Kingdom Transplant Support Service Authority (UKTSSA). They are summarized in Tables I and II. All heart donors were assessed according to clinical history, electrocardiographic changes, inotropic support, and arterial blood pressure measurement in addition to the operative evaluation. Intracardiac pressures were measured in $58 \%$ of the accepted donor hearts. Lung donors were assessed on the basis of clinical history, radiologic appearances, and duration of mechanical ventilation and arterial oxygen tension. Donor arterial oxygen tension was determined during mechanical ventila-
Table I. Heart, heart-lung, and lung donor criteria

\begin{tabular}{ll}
\hline Criteria & \multicolumn{1}{c}{ Organ } \\
\hline Meet criteria for brain death & Heart, lung, heart-lung \\
$\begin{array}{l}\text { Donor consent obtained } \\
\text { Age up to } 60 \text { years }\end{array}$ & $\begin{array}{l}\text { Heart, lung, heart-lung } \\
\text { Heart, lung, heart-lung }\end{array}$ \\
$\begin{array}{l}\text { Size: recipient } \pm 20 \% \text { body weight of } \\
\text { donor }\end{array}$ & Heart, heart-lung \\
ABO blood group compatibility & Heart, lung, heart-lung \\
No active infection & Heart, lung, heart-lung \\
No extracerebral malignant disease & Heart, lung, heart-lung \\
Normal heart, no history of pre-existing & Heart, heart-lung \\
$\quad$ heart disease & \\
Inotropic support $<10 \mu \mathrm{g} \cdot \mathrm{kg}^{-1} \cdot$ min $^{-1}$ & Heart, heart-lung \\
$\quad$ of dopamine & \\
No cardiac trauma & Heart, heart-lung \\
Anticipated ischemic time $<4$ hours & Heart, heart-lung \\
Satisfactory chest x-ray film & Lung, heart-lung \\
No active chest infection & Heart, lung, heart-lung \\
No chest trauma & Heart, lung, heart-lung \\
No history of asthma or chronic chest & Lung, heart-lung \\
$\quad$ condition & \\
Satisfactory arterial oxygenation & Lung, heart-lung \\
Satisfactory operative assessment & Heart, lung, heart-lung \\
\hline
\end{tabular}

tion at an inspired oxygen tension of 1.0 and a positive endexpiratory pressure of $5 \mathrm{~cm} \mathrm{H}_{2} \mathrm{O}$. Donors with a history of asthma or those with a smoking history of more than 20 cigarettes per day for more than 10 years were not considered for retrieval. Selective pulmonary vein gases were measured in $45 \%$ and $70 \%$ of accepted single and double lungs, respectively. Fiberoptic bronchoscopy was used to assess the bronchial tree in marginal donors. All donor hearts were preserved with the standard (1-2 L) St Thomas' Hospital cardioplegic solution. All DL and DD lung donor organs were preserved with Euro-Collins solution $(60 \mathrm{~mL} / \mathrm{kg})$. DX lungs were also preserved with Euro-Collins solution except in 3 cases of donor core cooling and in 6 procedures in which Papworth solution was used.

Experienced higher surgical trainee grade surgeons performed both heart and lung procurement for both DL and DD groups. In the DX group the organs were procured by experienced trainee surgeons in $85 \%$ of cases and by a consultant grade surgeon in $15 \%$.

\section{Assessment of recipient outcome}

Heart transplant recipients. The standard technique for orthotopic heart transplantation ${ }^{5}$ was used in 179 cases and the bicaval Wythenshawe technique ${ }^{6}$ in 101 cases. Heart transplant recipients were assessed by measurement of cardiac index at different intervals after the operation, requirement for major inotropic support, clinical features of rightsided heart failure, echocardiographic evaluation of left ventricular function, and by analysis of actuarial survival.

Lung transplant recipients. Standard previously described techniques ${ }^{7,8}$ were used for single, double, and heart-lung transplantation. Variables used to evaluate early outcome included alveolar-arterial oxygen gradient immediately after 
Table II. Donor suitability in hearts and lungs in the 3 groups

\begin{tabular}{|c|c|c|c|c|}
\hline Variable & DL group & DD group & DX group & $\mathrm{P}$ value \\
\hline Heart & $\mathrm{n}=171$ & $\mathrm{n}=58$ & $\mathrm{n}=51$ & \\
\hline 1. Age (y) & $31 \pm 7.3$ & $30 \pm 8.6$ & $30 \pm 9.4$ & 6 \\
\hline 2. Mean BP (mm Hg) & $72 \pm 12$ & $67 \pm 13$ & $70 \pm 10$ & .1 \\
\hline 3. Dopamine $\left(\mu \mathrm{g} \cdot \mathrm{kg}^{-1} \cdot \mathrm{min}^{-1}\right)$ & $6.5 \pm 0.9$ & $7.2 \pm 0.8$ & $7.4 \pm 0.3$ & .3 \\
\hline 4. CVP & $7.4 \pm 1.2$ & $8.2 \pm 0.8$ & $9.1 \pm 4$ & .2 \\
\hline Lungs & $\mathrm{n}=61$ & $\mathrm{n}=35$ & $\mathrm{n}=41$ & \\
\hline 1. Age & $34 \pm 11$ & $35 \pm 9$ & $36 \pm 10$ & .3 \\
\hline 2. $\mathrm{PaO}_{2}\left(100 \% \mathrm{O}_{2}\right.$ PEEP $\left.5 \mathrm{~mm}^{3}\right)$ & $346 \pm 24$ & $339 \pm 27$ & $351 \pm 19$ & .07 \\
\hline 3. Mechanical ventilation (h) & $53 \pm 15$ & $49 \pm 14$ & $53 \pm 12$ & .3 \\
\hline
\end{tabular}

$D L$ group, Local donors retrieved by our surgical team; $D D$ group, distant donors retrieved by our surgical team; $D X$ group, distant donors retrieved by another surgical team; $B P$, blood pressure; $C V P$, central venous pressure; $P E E P$, positive end-expiratory pressure.

Table III. Summary of recipient's profile for heart and lung transplantation

\begin{tabular}{lcccc}
\hline Variable & DL group & DD group & DX group & P value \\
\hline Hearts & $\mathrm{n}=171$ & $\mathrm{n}=58$ & $\mathrm{n}=51$ & .6 \\
$\quad$ Ischemic heart disease & $82(47 \%)$ & $31(53 \%)$ & $22(43 \%)$ & .5 \\
Cardiomyopathy & $79(48 \%)$ & $25(43 \%)$ & $27(52 \%)$ & .8 \\
Others & $10(5 \%)$ & $\mathrm{n}=35$ & $\mathrm{n}=41$ & .8 \\
Lungs & $\mathrm{n}=61$ & $6(34 \%)$ & $6(29 \%)$ & .5 \\
CF & $11(36 \%)$ & $13(37 \%)$ & $14(41 \%)$ & .8 \\
EMP & $21(39 \%)$ & $8(23 \%)$ & $10(25 \%)$ & .9 \\
IPF & $12(20 \%)$ & $2(6 \%)$ & $2(5 \%)$ & $9 / 41$ \\
Others & $3(5 \%)$ & $6 / 35$ & \\
Tx type (SLT/DLT) & $14 / 61$ & 5 & \\
\hline
\end{tabular}

$D L$ group, Local donors retrieved by our surgical team; $D D$ group, distant donors retrieved by our surgical team; $D X$ group, distant donors retrieved by another surgical team; $C F$, cystic fibrosis; $E M P$, emphysema; $I P F$, idiopathic pulmonary fibrosis; $T x$, transplantation; $S L T$, single lung transplantation; $D L T$, double lung transplantation.

transplantation on return to the intensive therapy unit (ITU) and at up to 72 hours after the operation, duration of mechanical ventilation, length of ITU stay, length of hospital stay, and 30-day mortality. Actuarial survival was evaluated.

Statistical analysis. Results are expressed as mean \pm standard deviation. Statistical analysis of results between different groups was performed by analysis of variance, $\chi^{2}$, or Scheffé $\mathrm{F}$ test. Actuarial survival was evaluated by the Kaplan-Meier method.

\section{Results}

\section{Donor suitability}

Heart transplantation. Age, mean arterial blood pressure, degree of inotropic support, and central venous pressure were equivalent in the 3 groups $(P=.6, .1, .3$, and .2, respectively, Table II). Operative assessment of heart donors was satisfactory in the 3 groups.

Lung transplantation. No significant difference among the 3 groups was observed in terms of age, arterial oxygen tension, and duration of mechanical ventilation $(P=.3, .07$, and .3 respectively, Table II). Operative assessment of lung donors was satisfactory in the 3 groups.
Recipient profile. No significant difference in age, sex, and recipient diagnosis was observed among the 3 groups in heart or lung transplantation (Table III).

\section{Early recipient outcome}

Heart transplantation. No difference was observed in the need for early mechanical support $(P=.6)$ or duration of mechanical $(P=.09)$ or ventilatory $(P=.08)$ support among the 3 groups. The DL group had shorter ischemic times (Table IV), a lower requirement for mechanical ventilation, and a shorter ITU stay than the DD and DX groups (Table V). However, these differences did not achieve statistical significance $(P=.07$ for ischemic time, .08 for ventilation time, and .4 for ITU stay).

Lung transplantation. The 3 groups were similar with regard to arterial oxygen saturation $(P=.07)$, duration of mechanical ventilation $(P=.09)$, ITU stay $(P=.2)$, and total hospital stay $(P=.3)$. The DL group had a lower requirement for mechanical ventilation and a shorter ITU stay than did the DD and DX groups (Table VI). However, these differences did not achieve significance values $(P=.07$ for ischemic time, .09 for ventilation time, and .2 for ITU stay, respectively) (Tables IV and VI). 
Table IV. Comparison of ischemic time and use of CPB during lung implantation

\begin{tabular}{lcccc}
\hline Variable & DL group & DD group & DX group & P value \\
\hline Heart & $\mathrm{n}=171$ & $\mathrm{n}=58$ & $\mathrm{n}=51$ & $170 \pm 19$ \\
$\quad$ Ischemic time (min) & $155 \pm 26$ & $167 \pm 18$ & $\mathrm{n}=41$ & .07 \\
Lungs & $\mathrm{n}=61$ & $\mathrm{n}=35$ & $216 \pm 26$ & .09 \\
$\quad$ Ischemic time (min) & $208 \pm 47$ & $200 \pm 25$ & $391 \pm 9$ & .07 \\
SLT & $378 \pm 18$ & $368 \pm 31$ & 20.9 & .2 \\
DLT & 25.6 & 22.3 & \\
Use of CBP in lung transplantation (\%) & & & \\
\hline
\end{tabular}

Ischemic time for the DLT group is the ischemic time for the second lung. DL group, Local donors retrieved by our surgical team; $D D$ group, distant donors retrieved by our surgical team; $D X$ group, distant donors retrieved by another surgical team; SLT, single lung transplantation; $D L T$, double lung transplantation.

Table V. Result of early recipient outcome of heart transplantation in 3 groups

\begin{tabular}{lcccc}
\hline Variable & DL group $(n=171)$ & DD group $(n=58)$ & DX group $(n=51)$ & P value \\
\hline Cardiac index $\left(\mathrm{L}^{2} \mathrm{~m}^{2}\right)$ & $2.6 \pm 0.4$ & $2.7 \pm 0.6$ & $2.5 \pm 0.7$ & .4 \\
EF\% $>55 \%$ & $86 \%(154 / 171)$ & $82 \%(50 / 58)$ & $88 \%(44 / 51)$ & .4 \\
Mechanical support (IABP) & $10.5 \%(18 / 171)$ & $11 \%(7 / 58)$ & $10 \%(5 / 51)$ & .6 \\
Right-sided heart failure & $23 \%(41 / 171)$ & $25 \%(14 / 58)$ & $26 \%(13 / 51)$ & .5 \\
Days on ventilator & $2.1 \pm 0.9$ & $2.4 \pm 0.8$ & $2.7 \pm 1.1$ & .08 \\
Days in ITU & $4.5 \pm 0.9$ & $4.8 \pm 1.6$ & $4.9 \pm 1.1$ & .4 \\
Length of hospital stay (d) & $22 \pm 4.4$ & $26 \pm 3.6$ & $25 \pm 3.4$ & .3 \\
Death < 30 days & $9.1 \%(15 / 171)$ & $9.1 \%(5 / 58)$ & $8.3 \%(4 / 51)$ & .5 \\
\hline
\end{tabular}

$\overline{D L}$ group, Local donors retrieved by our surgical team; $D D$ group, distant donors retrieved by our surgical team; $D X$ group, distant donors retrieved by another surgical team; $E F$, ejection fraction; IABP, intra-aortic balloon pumping; ITU, intensive therapy unit.

Table VI. Results of early recipient outcome of lung transplantation in 3 groups

\begin{tabular}{|c|c|c|c|c|}
\hline Variable & $D L \operatorname{group}(n=61)$ & DD group $(n=35)$ & $D X$ group $(n=41)$ & $\mathrm{P}$ value \\
\hline \multicolumn{5}{|l|}{ Satisfactory oxygenation } \\
\hline Immediate & $358 \pm 19$ & $345 \pm 17$ & $329 \pm 21$ & .07 \\
\hline 24 hours & $123 \pm 11$ & $130 \pm 17$ & $127 \pm 9$ & .5 \\
\hline 3 days & $116 \pm 19$ & $135 \pm 9$ & $109 \pm 17$ & .08 \\
\hline Satisfactory x-ray appearance & $83 \%(50 / 61)$ & $82 \%(29 / 35)$ & $79 \%(32 / 41)$ & .3 \\
\hline Days on ventilator & $6.8 \pm 2.9$ & $7.8 \pm 3.1$ & $8.1 \pm 0.5$ & .09 \\
\hline Days in ITU & $9.9 \pm 3.5$ & $9.1 \pm 5.2$ & $10.7 \pm 4.3$ & .2 \\
\hline Length of hospital stay (days) & $31 \pm 3.3$ & $33 \pm 2.8$ & $33 \pm 2.9$ & .3 \\
\hline Death $<30$ days & $9.9 \%(6 / 16)$ & $10.5 \%(4 / 35)$ & $12.8 \%(5 / 41)$ & .2 \\
\hline
\end{tabular}

$\overline{D L}$ group, Local donors retrieved by our surgical team; $D D$ group, distant donors retrieved by our surgical team; $D X$ group, distant donors retrieved by another surgical team; ITU, intensive therapy unit.

\section{Survival}

Heart transplantation. Thirty-day mortality was not significantly different among the 3 groups $(9.1 \%, 9.1 \%$, and $8.3 \%$ for the DL, DD, and DD groups, respectively; $P=.5$, Table V). Actuarial 1- and 3-year survivals, respectively, were $83 \%$ and $78 \%$ for the DL group, $80 \%$ and $75 \%$ for the DD group, and $82 \%$ and $76 \%$ for the DX group $(P=.4$ for 1-year survival and $P=.5$ for 3-year survival, Fig 2).

Lung transplantation. Thirty-day mortality was not significantly different among the 3 groups $(9.9 \%$,
$10.5 \%$, and $12.8 \%$ for the DL, DD, and DX groups, respectively, $P=.2$, Table VI). Actuarial 1-year and 3year survivals were $79 \%$ and $64 \%$, respectively, for the DL group, $75 \%$ and $63 \%$, respectively, for the DD group, and $77 \%$ and $60 \%$, respectively, for the DX group $(P=.3$ for 1 -year survival and $P=.4$ for 3 -year survival, Fig 3$)$.

Changes in hospital visits and traveling distance. The average number of donor hospitals visited by our transplant team decreased from 46 hospitals in 1992 to 16 hospitals in 1996 . The distance traveled by our 


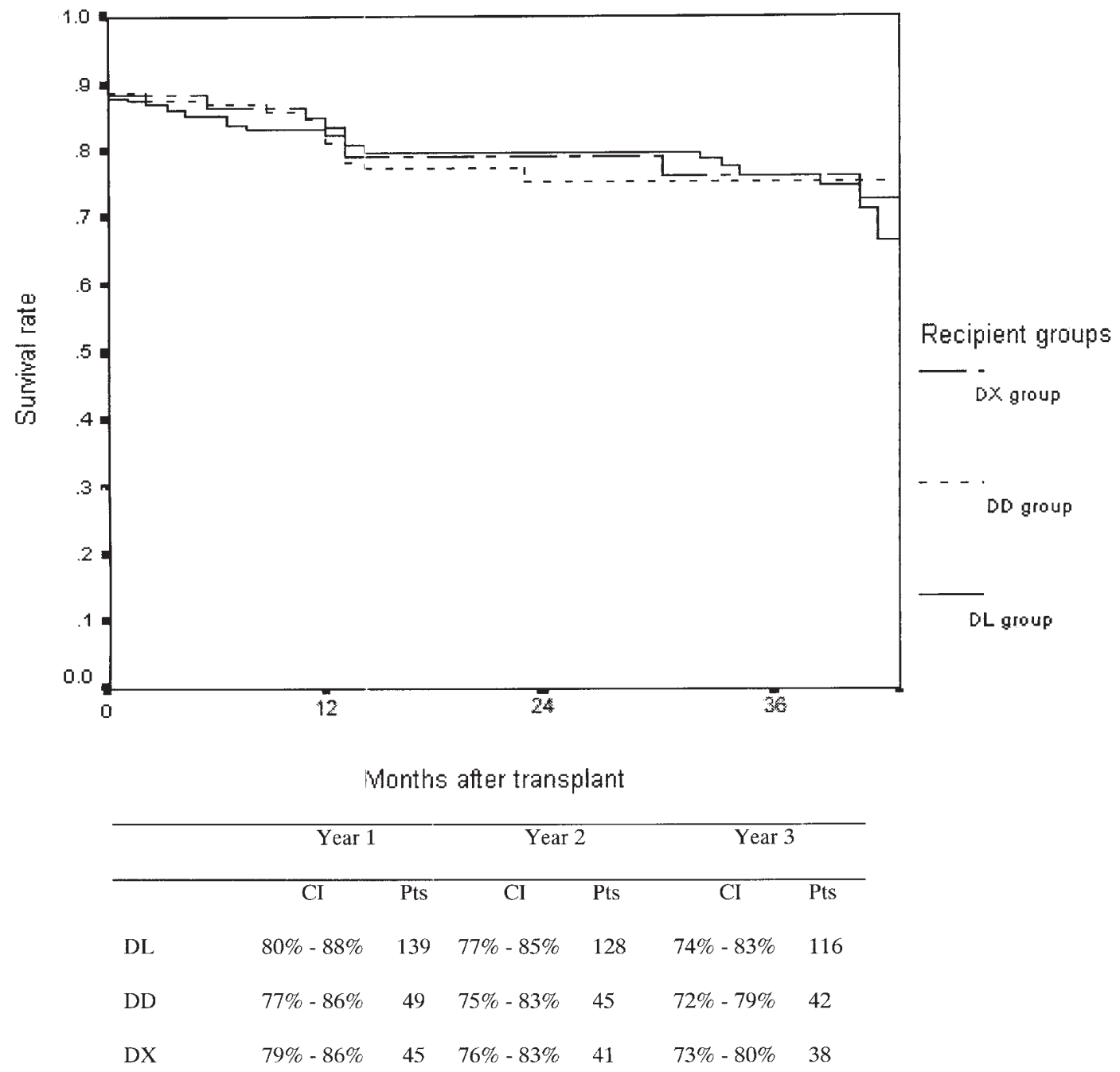

Fig 2. Survival figures for the heart transplant recipients. $C I$, Confidence interval of survival; Pts, number of patients traced in each group; DL group, local donors retrieved by our surgical team; DD group, distant donor retrieved by our surgical team; $D X$ group, distant donors retrieved by another surgical team.

transplant team decreased from an average of 183 miles per retrieval in 1992 to 76 miles per retrieval in 1996.

Heart-lung transplantation. The number of heart-lung transplantation procedures has declined in our center since we successfully introduced our double lung transplantation program. This correlated with the national decline in the performance of heart-lung transplantation from 94 transplants in 1994 to 44 operations in 1997. ${ }^{9}$ We do not think that the zonal allocation would have a direct impact on the heart-lung transplantation activity.

\section{Discussion}

As the techniques of heart and lung preservation have improved, distant thoracic organ retrieval has become standard. ${ }^{10-12}$ Previously each transplant center sent its own team to the donor hospital for retrieval. Since the introduction of zonal organization to the United Kingdom in November 1993, this has been unnecessary, because the zonal team is usually present and capable of harvesting the donor organs. The UKTSSA initial data highlighted the significance of the zonal allocation of thoracic organs in the United Kingdom. Within the zonal allocation scheme, more than $23 \%$ of hearts and 55\% of lungs offered for donation were retrieved by a transplant team from a center not responsible for the subsequent transplant procedure. ${ }^{13}$ The exchange rate of thoracic organs between the United Kingdom transplant centers has increased by $4-$ or 5 - 


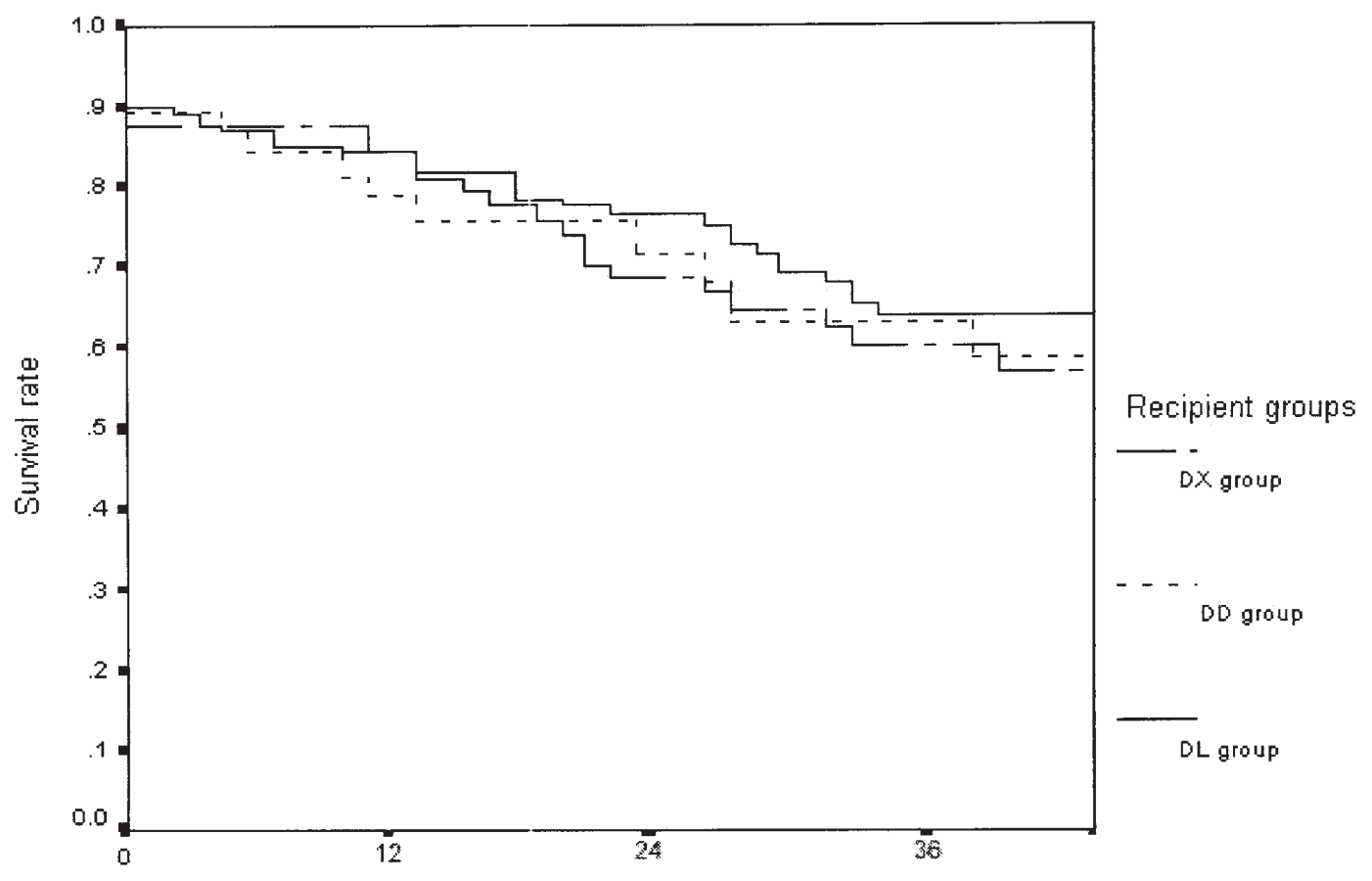

Month:s after transplant

\begin{tabular}{ccccccc}
\hline & \multicolumn{2}{c}{ Year 1 } & \multicolumn{2}{c}{ Year 2 } & \multicolumn{2}{c}{ Year 3 } \\
\hline & CI & Pts & CI & Pts & CI & Pts \\
DL & $76 \%-83 \%$ & 40 & $67 \%-75 \%$ & 32 & $57 \%-69 \%$ & 24 \\
DD & $71 \%-80 \%$ & 22 & $68 \%-77 \%$ & 18 & $56 \%-67 \%$ & 14 \\
DX & $72 \%-80 \%$ & 24 & $71 \%-77 \%$ & 21 & $52 \%-64 \%$ & 15
\end{tabular}

Fig 3. Survival figures for the lung transplant recipients. $C I$, Confidence interval of survival; Pts, number of patients traced in each group; $D L$ group, local donors retrieved by our surgical team; DD group, distant donor retrieved by our surgical team; $D X$ group, distant donors retrieved by another surgical team.

fold since its introduction. The scheme has allowed donor hospitals to be visited by the same transplant team and has improved efficiency because of less duplication of surgical staff. It has also offered significant reduction in the traveling of transplant surgeons between different zones.

At our institution DL and DD groups started after commencement of our heart transplantation program in 1987. A small number of DX donor operations (15\% of the total DX organs) also occurred before the introduction of zonal allocation. After 1993, our activity has been distributed between the DL and DX groups in addition to an ongoing DD group, which comprises lung donors continuously offered to us from surround- ing European countries. In these cases we have to send our own team to perform the retrieval operation.

Potentially, our results could have been confounded by the improvement in outcome of transplantation that occurred during the period of the study. However, analysis of our data failed to demonstrate a significant impact of era on our results. More than $80 \%$ of our lung transplantation activity was performed after 1993, and all lung transplants performed before the zonal allocation belonged to only 1 group (DL). For heart transplantation, we did not find a significant difference in operative or first-year survival between recipients treated before or after 1993 (operative mortality and firstyear survival were, respectively, $11 \%$ and $79 \%$ for 
heart transplant recipients treated before 1993 compared with an operative mortality of $8 \%$ and a first-year survival of $87 \%$ for recipients treated after $1993(P=.6$ and .1, respectively). A similar outcome between both eras in our study is supported by data published by the International Society of Heart and Lung Transplantation in their annual report. ${ }^{14}$

In our series the ischemic time of the DD and DX groups was not significantly longer than that of the DL group. This could be explained by the early timing of the recipient operation when distant donor organs were used. Other factors include the transfer by air of organs in more than $90 \%$ of DD and DX donor operations, the central location of our center within the United Kingdom, and the relatively short distance $(3$ miles $)$ between our hospital and the local airport.

A major concern at the institution of the new zonal organ allocation in the United Kingdom was the potential implications for the outcome of thoracic organ transplantation at each center. This study has demonstrated that there has been no significant change in outcome since November 1993 and that the team has not affected the outcome used for retrieval. We did not detect a difference in early outcome using distant donor organs retrieved by our team and those using donor organs retrieved by other teams. Although transplantation using local lung donors tended to have a better early outcome than those using distant donors, these differences did not achieve statistical significance. No difference in 30-day mortality and actuarial survival was observed among the 3 groups.

The impact of this zonal organ allocation on the number of heart and lungs transplants is still unclear. Certainly the number of transplants performed in our center correlates with the number of revivals performed in our zone. Initially, we noted an increase in the number of retrievals performed in our zonal area (from 63 organs in 1993 to 80 organs in 1995), and this was associated with an increased number of thoracic organ transplants performed in our center. However, the number of thoracic organ retrievals and subsequently the activity of transplants performed have declined to a number comparable with that observed before zonal allocation.
In conclusion, the application of zonal organ allocation for thoracic organs in the United Kingdom has been safe and successfully applied to our transplantation program. We have used donor organs retrieved by other teams and achieved satisfactory outcomes for both heart and lung transplantation.

We acknowledge Dr Alison Wynn Hann from the University Department of Statistics at Withington Hospital for her assistance during preparation and revision of this manuscript.

\section{REFERENCES}

1. Dark JH, Locke T, Rogers C, Wallwork J. Zonal allocation for thoracic organs in the UK (abstract). J Heart Lung 1995;14:43.

2. Evans RW, Orians EC, Ascher NL. The potential supply of organ donor: an assessment of the efficiency of organ procurement effort in the United State. JAMA 1992;267:239-46.

3. El Oakley RM, Yonan NA, Simpson BM, Deiraniya AK. Extended criteria for cardiac allograft donors: a consensus study. J Heart Lung Transplant 1996;15:225-9.

4. Sundaresan S, Trachiotis GD, Aoe M, Patterson GA, Cooper JD. Donor lung procurement: assessment and operative technique. Ann Thorac Surg 1993;56:1409-13.

5. Lower RR, Stofer RC, Shumway NE. Homovital transplantation of the heart. J Thorac Cardiovasc Surg 1961;41:196-201.

6. Sarsam MA, Campbell CS, Yonan NA, Deiraniya AK, Rahman AN. An alternative technique in orthotopic cardiac transplantation. J Card Surg 1993;8:344-9.

7. Patterson GA, Cooper JD. Lung transplantation for emphysema. Chest Surg Clin North Am 1995;5:851-68.

8. Pasque MK, Cooper JD, Kaiser LR, Haydock DA, Triantafillou A, Trulok EP. Improved technique for bilateral lung transplantation: rational and initial clinical experience. Ann Thorac Surg 1990;49:785-91.

9. Transplant activity 1985-1996. UKTSSA report.

10. Todd TR, Goldberg M, Koshal A, et al. Separate extraction of cardiac and pulmonary grafts from single organ donors. Ann Thorac Surg 1988;46:356-9.

11. Kirk AJB, Colquhoum IW, Dark JH. Lung preservation: a review of current practice and future directions. Ann Thorac Surg 1993; 56:990-1000.

12. Wahlers T, Schafers HJ, Cremer J, Hirts S, Haversich A. Technique and results of organ sharing for heart and isolated single or doublelung transplantation. Transplant Proc 1991;23:2675-7.

13. Transplant activity 1996. UKTSSA annual report (April 1996March 1997). p. 26-31.

14. Hospend JD, Bennett LE, Keck BM, Fiol B, Boucek MM, Novick RJ. The Registry of the International Society for Heart and Lung Transplantation. J Heart Lung 1998;17:665-8. 